\title{
MTHFR C677T and MTR A2756G polymorphisms and the homocysteine lowering efficacy of different doses of folic acid in hypertensive Chinese adults
}

Xianhui Qin ${ }^{1}$, Jianping $\mathrm{Li}^{2}$, Yimin $\mathrm{Cui}^{3}$, Zeyuan Liư ${ }^{4}$ Zhigang Zhao ${ }^{5}$, Junbo Ge${ }^{6}$, Deming Guan ${ }^{7}$, Jian $\mathrm{Hu}^{8}$, Yanni Wang ${ }^{9}$, Fumin Zhang ${ }^{10}$, Xin $\mathrm{Xu}^{11}$, Xiaobin Wang ${ }^{12}$, Xiping $\mathrm{Xu}^{1^{*}}$ and Yong Huo ${ }^{2^{*}}$

\begin{abstract}
Background: This study aimed to investigate if the homocysteine-lowering efficacy of two commonly used physiological doses $(0.4 \mathrm{mg} / \mathrm{d}$ and $0.8 \mathrm{mg} / \mathrm{d})$ of folic acid (FA) can be modified by individual methylenetetrahydrofolate reductase (MTHFR) C677T and/or methionine synthase (MTR) A2756G polymorphisms in hypertensive Chinese adults.

Methods: A total of 480 subjects with mild or moderate essential hypertension were randomly assigned to three treatment groups: 1) enalapril only (10 mg, control group); 2) enalapril-FA tablet [10:0.4 mg (10 mg enalapril combined with $0.4 \mathrm{mg}$ of FA), low FA group]; and 3) enalapril-FA tablet (10:0.8 mg, high FA group), once daily for 8 weeks.

Results: After 4 or 8 weeks of treatment, homocysteine concentrations were reduced across all genotypes and FA dosage groups, except in subjects with MTR 2756AG /GG genotype in the low FA group at week 4. However, compared to subjects with MTHFR 677CC genotype, homocysteine concentrations remained higher in subjects with $C T$ or $\Pi$ genotype in the low FA group ( $P<0.05$ for either of these genotypes) and $\Pi$ genotype in the high FA group $(P<0.05)$. Furthermore, subjects with $\Pi$ genotype showed a greater homocysteine-lowering response than did subjects with CC genotype in the high FA group (mean percent reduction of homocysteine at week 8: CC $10.8 \%$ vs. T: $22.0 \%, P=0.005$ ), but not in the low FA group (CC $9.9 \%$ vs. $\Pi 11.2 \%, P=0.989$ ).

Conclusions: This study demonstrated that MTHFR C677T polymorphism can not only affect homocysteine concentration at baseline and post-FA treatment, but also can modify therapeutic responses to various dosages of FA supplementation.
\end{abstract}

Keywords: Folic acid supplementation, MTHFR C677T polymorphism, MTR A2756G polymorphism, Homocysteinelowering efficacy

\section{Background}

Traditional risk factors are estimated to account for only part of cardiovascular disease (CVD) risk [1]. Non-traditional risk factors such as increased homocysteine concentrations are believed to be causally related to CVD [2]. The interactive effect between hypertension and

\footnotetext{
* Correspondence: xipingxu18@gmail.com; huoyong@263.net.cn 'Institute of Biomedicine, Anhui Medical University, Hefei, China ${ }^{2}$ Department of Cardiology and Heart Center, Peking University First Hospital, Beijing, China

Full list of author information is available at the end of the article
}

hyperhomocysteinemia on the risk of CVD has received great attention [3]. Our previous meta-analysis [4] suggested that folic acid (FA) supplementation could significantly reduce the risk of stroke by $18 \%$ [Relative Risk (RR):0.82, 95\% Confidence Interval (CI): 0.68-1.00; $P=$ $0.045)$, and an even greater beneficial effect was seen in those trials with no or partial FA fortification (RR: 0.75, 95\%CI: 0.62-0.91; $P=0.003)$. Furthermore, FA supplementation was found to significantly reduce CVD risk in patients with end stage renal disease or advanced chronic kidney disease (creatinine clearance $<30 \mathrm{~mL} / \mathrm{min}$ ) by $15 \%$

\section{() Biomed Central}

(c) 2012 Qin et al; licensee BioMed Central Ltd. This is an Open Access article distributed under the terms of the Creative Commons Attribution License (http://creativecommons.org/licenses/by/2.0), which permits unrestricted use, distribution, and reproduction in any medium, provided the original work is properly cited. 
(RR: 0.85; 95CI: 0.76-0.96, $\mathrm{P}=0.009$ ), particularly in trials with no or partial FA fortification (RR: 0.80; 95\% CI: 0.65$0.99 ; \mathrm{p}=0.04$ ) [5]. These findings underscore the importance of effectively lowering homocysteine concentration in the prevention of CVD, particularly in populations with a high prevalence of hypertension and hyperhomocystienemia but without FA fortification.

Methylenetetrahydrofolate reductase (MTHFR) and methionine synthase (MTR) are the main regulatory enzymes for homocysteine metabolism. MTHFR converts 5, 10-methylene-THF into 5-methyl-THF. Polymorphism of MTHFR C677T leads to a reduction in enzyme activity, which may lead to an increased concentration of plasma homocysteine and lower levels of serum folate, particularly in those with low folate intake [6]. MTR catalyzes the demethylation of 5-methyl-THF to THF and the remethylation (using the methyl group donated by 5 -methyl-THF) of homocysteine to methionine. A common polymorphism in the MTR gene (A2756G) also seems to influence plasma homocysteine [7].

To our knowledge, no published trial has investigated if the homocysteine-lowering efficacy of two commonly used doses $(0.4 \mathrm{mg} / \mathrm{d}$ and $0.8 \mathrm{mg} / \mathrm{d})$ of FA can be modified by individual MTHFR C677T and MTG A2756G polymorphisms in hypertensive adults without FA fortification. In this report, we analyzed the data from a randomized, double-blind, controlled trial that included three intervention groups: 1 ) enalapril only (10 mg, control group); 2) enalapril-FA tablet (10 mg enalapril combined with $0.4 \mathrm{mg}$ of FA, low FA group); and 3) enalapril-FA tablet (10 mg enalapril combined with $0.8 \mathrm{mg}$ of FA, high FA group), once daily for 8 weeks. We sought to assess if MTHFR or MTR genotypes can influence a change in plasma homocysteine concentration in response to each of the two different dosages of FA supplementation.

\section{Methods}

This was a multicenter, randomized, double-blind controlled trial in hypertensive Chinese adults (clinicaltrials. gov; identifier: NCT00520247) [8]. The details regarding "Subjects", "Intervention and data collection", "Laboratory methods", and "Statistical Analysis" have been previously described [9]. Briefly, 480 patients with mild or moderate hypertension were recruited from six hospitals in different Chinese regions (Ha'erbin, Shanghai, Shenyang, Beijing, Xi'an, and Nanjing) from September-December 2005. Eligible subjects were randomly and double-blindly assigned to one of the three treatment groups: 1) enalapril tablet (10 mg, control group); 2) enalapril-FA tablet (10 mg enalapril combined with $0.4 \mathrm{mg}$ of FA, low FA group); or 3) enalapril-FA tablet (10 mg enalapril combined with $0.8 \mathrm{mg}$ of FA, high FA group), once daily for 8 weeks.

Demographic and clinical information were obtained at baseline. Blood homocysteine concentrations were examined at baseline and at 4 and 8 weeks of the trial. MTHFR C677T and MTR A2756G genotypes were determined for each study subject.

All analyses were performed according to the principle of intention to treat. Homocysteine and folate concentrations in the natural logarithms (due to their positively skewed distributions) were analyzed as continuous variables. The relative change of homocysteine is expressed as the change of homocysteine after FA treatment relative to baseline concentration [(homocysteine after treatmenthomocysteine at baseline)/(homocysteine at baseline)], which was applied as the primary outcome. Multivariable regression models were applied to compare the relative change of homocysteine among different groups. The additive models were used to test the gene-gene interactive effect between the MTHFR C677T and the MTR A2756G polymorphisms on the homocysteine-lowering efficacy of FA supplementation with and without adjustments for the potential non-genetic confounding factors. Statistical analysis was performed using SAS software version 6.12 (SAS Institute, Cary, NC, USA).

\section{Results}

A total of 480 patients were recruited for this study. This analysis excluded 35 subjects who were ineligible to participate in the trial (7 in control group: 9 in low FA group; 8 in high FA group) or without data of MTHFR genotype (2 in high FA group) or MTR A2756G (1 in control group; 4 in low FA group; 4 in high FA group). Accordingly, a total of 445 subjects were included in our final analysis.

The prevalence of MTHFR C677T polymorphisms 677 CC, 677 CT, and 677TT were 0.256, 0.497, and 0.247, respectively. The prevalence of the 2756AA, 2756AG, and 2756 GG genotypes were $0.820,0.171$, and 0.009 , respectively. This population had no significant deviations in genotype distributions from expected Hardy-Weinberg equilibrium. Because there were only four subjects homozygous for the G2756 allele, the genotypes AG and GG were combined for statistical analyses.

Table 1 shows the baseline characteristics of the subjects according to MTHFR and MTR genotypes. Subjects with MTHFR 677 TT genotype had significantly higher homocysteine concentrations (median: $17.5 \mu \mathrm{mol} / \mathrm{L}$ ) than did those with CT $(11.5 \mu \mathrm{mol} / \mathrm{L})$ or $\mathrm{CC}(11.1 \mu \mathrm{mol} / \mathrm{L})$ genotype ( $\mathrm{P}<0.01$ for either of these genotypes). However, homocysteine concentrations did not differ among subjects with different genotypes of the MTR gene. There was no significant interactive effect between MTHFR C677T and MTR A2756G polymorphisms on homocysteine concentrations at baseline.

Compared to baseline, after 4 or 8 weeks of FA treatment decreases in plasma homocysteine concentrations were seen across all MTHFR C677T genotypes and FA dosage groups (Table 2). Even after the treatment, 
Table 1 Baseline characteristics of participants by MTHFR C677T or MTR A2756G polymorphism ${ }^{1}$

\begin{tabular}{|c|c|c|c|c|c|c|c|c|}
\hline & \multirow[b]{2}{*}{ All } & \multicolumn{4}{|c|}{ MTHFR C677T } & \multicolumn{3}{|c|}{ MTR A2756G } \\
\hline & & $\mathrm{CC}$ & CT & $\pi$ & $P$ & AA & AG/GG & $P$ \\
\hline $\mathrm{N}$ & 445 & 114 & 221 & 110 & & 365 & 80 & \\
\hline Sex(Male), no.(\%) & $191(42.9)$ & $51(44.7)$ & $91(41.2)$ & $49(44.5)$ & 0.761 & $155(42.5)$ & $36(45.0)$ & 0.678 \\
\hline Age, yrs & $57.0(9.8)$ & $57.0(9.5)$ & $56.4(9.6)$ & $58.2(10.4)$ & 0.284 & $57.0(9.8)$ & $57.0(9.9)$ & 0.971 \\
\hline $\mathrm{BMI}, \mathrm{kg} / \mathrm{m}^{2}$ & $25.7(3.5)$ & $25.5(3.9)$ & 25.8(3.3) & $25.7(3.3)$ & 0.758 & $25.8(3.5)$ & $25.2(3.5)$ & 0.137 \\
\hline $\mathrm{SBP}, \mathrm{mmHg}$ & $154.0(11.2)$ & $154.0(11.5)$ & 153.8(11.4) & $154.5(10.5)$ & 0.863 & 153.8(11.2) & $155.1(11.2)$ & 0.324 \\
\hline $\mathrm{DBP}, \mathrm{mmHg}$ & $93.0(8.3)$ & $92.4(8.5)$ & $93.4(7.8)$ & $92.8(9.0)$ & 0.530 & 93.3(8.0) & $91.4(9.4)$ & 0.052 \\
\hline $\mathrm{FPG}, \mathrm{mmol} / \mathrm{L}$ & $5.5(1.3)$ & $5.5(1.5)$ & $5.4(1.2)$ & $5.7(1.2)$ & 0.312 & $5.5(1.3)$ & $5.5(1.2)$ & 0.865 \\
\hline $\mathrm{TC}, \mathrm{mmol} / \mathrm{L}$ & $5.0(1.1)$ & $5.0(1.4)$ & $4.9(1.0)$ & $5.1(1.0)$ & 0.555 & $5.0(1.1)$ & $4.9(1.1)$ & 0.259 \\
\hline $\mathrm{HDL}-\mathrm{C}, \mathrm{mmol} / \mathrm{L}$ & $1.3(0.4)$ & $1.3(0.4)$ & $1.3(0.4)$ & $1.3(0.4)$ & 0.479 & $1.3(0.4)$ & $1.3(0.3)$ & 0.542 \\
\hline $\mathrm{TG}, \mathrm{mmol} / \mathrm{L}$ & $1.7(1.2)$ & $1.7(1.0)$ & $1.8(1.2)$ & $1.7(1.5)$ & 0.970 & $1.8(1.3)$ & $1.6(0.8)$ & 0.252 \\
\hline Creatinine, $\mu \mathrm{mol} / \mathrm{L}$ & $69.5(17.5)$ & $68.0(17.5)$ & $69.2(17.3)$ & $71.9(17.9)$ & 0.233 & $69.2(17.9)$ & $71.3(15.6)$ & 0.334 \\
\hline Folate, $\mathrm{nmol} / \mathrm{L}^{2}$ & $12.6(1.5)[12.3]$ & $13.7(1.4)[13.4]$ & $13.0(1.5)[12.6]$ & $11.0(1.4)[10.8] *$ & $<0.001$ & $12.8(1.5)[12.5]$ & $11.9(1.5)[11.6]$ & 0.107 \\
\hline Homocysteine, $\mu \mathrm{mol} / \mathrm{L}^{2}$ & $13.2(1.6)[12.1]$ & $11.2(1.4)[11.1]$ & $12.0(1.4)[11.5]$ & $18.8(1.8)[17.5] *$ & $<0.001$ & $13.1(1.6)[12.1]$ & $13.3(1.6)[12.6]$ & 0.794 \\
\hline
\end{tabular}

$\mathrm{BMI}=$ body mass index, $\mathrm{SBP}=$ systolic blood pressure, $\mathrm{DBP}=$ diastolic blood pressure, FPG = fasting plasma glucose,

$\mathrm{TC}=$ total cholesterol, HDL-C = high-density lipoprotein cholesterol, TG = triglyceride;

${ }^{1}$ Means (SD); ${ }^{2}$ geometric mean (anti-log SD), median in brackets; ${ }^{*}$ Significantly different from the CT or CC genotype, $P<0.001$.

homocysteine concentrations in subjects with TT and $\mathrm{CT}$ genotypes remained significantly higher at week 4 or week 8 ( $P<0.05$ for either of these genotypes) compared to those with CC genotype in the low FA group. In contrast, only subjects with TT genotype had higher homocysteine concentrations compared to CC genotype $(P<0.05)$ at week 4 or week 8 in the high FA group (Table 2).

Furthermore, in the high FA group subjects with TT genotype showed a significantly greater homocysteine-lowering response than did subjects with $\mathrm{CC}$ genotype at week 4 or week 8 , with or without adjustments for the relevant demographic and clinical characteristics at baseline (mean percent reduction of homocysteine at week 4: CC $5.9 \%$ vs. TT: $20.3 \%, P<0.001$; mean percent reduction of homocysteine at week 8 : CC $10.8 \%$ vs. TT: $22.0 \%, P=$ 0.005). This heightened level of response was not shown in the low FA group (mean percent reduction of homocysteine at week 4 : CC $8.8 \%$ vs. TT $10.6 \%, P=0.769$; mean percent reduction of homocysteine at week 8: CC $9.9 \%$ vs. TT $11.2 \%, P=0.989$ ) (Table 2).

The change in homocysteine was positively related to the baseline homocysteine concentrations in all genotypes and FA dosage groups. When baseline homocysteine also was adjusted, subjects with TT genotype seemed to have an attenuated homocysteine lowering response compared to subjects with $C \mathrm{C}$ genotype $(P=$ 0.036 at week $4, P=0.002$ at week 8$)$ in the low FA group, but not in the high FA group $(P=0.449$ at week $4, P=0.414$ at week 8 ). Our results did not substantially alter with further adjustment for baseline folate concentration and folate change after treatment.

Compared to baseline, after 4 or 8 weeks of FA treatment, decreases in plasma homocysteine concentrations were seen in all MTR A2756G genotypes and FA dosage groups, except in subjects with AG/GG genotype in the low FA group at week 4. However, neither the homocysteine concentration post-FA treatment nor the homocysteine-lowering response of FA supplementation was affected by MTR A2756G polymorphism (Table 3). There was no significant interactive effect between MTHFR C677T and MTR A2756G polymorphisms on the homocysteine-lowering efficacy of different doses of FA supplementation with or without adjustments for potential non-genetic confounding factors.

We obtained similar results when we restricted our analyses to subjects who fully complied with the protocol (consuming at least $80 \%$ of all of the prescribed drugs) during the treatment periods (per protocol set, $\mathrm{n}=381$ ) (data not shown).

\section{Discussion}

Both a previous dose-finding trial [10] and a doseresponse trial [11] have discussed the relationship between homocysteine-lowering efficacy and optimal dose of FA supplementation, but without considering the possible modifying effect of MTHFR C677T polymorphism. A more recent study [12] evaluated the effect of MTHFR C677T polymorphism on the response to different doses of FA supplementation $(0.1 \mathrm{mg} / \mathrm{d}, 0.4 \mathrm{mg} / \mathrm{d}, 4 \mathrm{mg} / \mathrm{d}$ and 4 $\mathrm{mg} /$ week) in northern Chinese women of childbearing age and reported that the MTHFR 677 TT genotype was an independent predictor of plasma homocysteine concentrations, irrespective of FA dose, which was consistent with our results. However, the study population consisted of young women and the FA dosage category was not optimal, being either too low $(0.1 \mathrm{mg} / \mathrm{d})$ or too high $(4 \mathrm{mg} / \mathrm{d})$. Furthermore, plasma homocysteine concentrations 
Table 2 Response of plasma homocysteine to different doses and duration of folic acid supplementation by MTHFR C677T genotypes

\begin{tabular}{|c|c|c|c|c|c|c|c|c|c|c|}
\hline & \multirow[t]{2}{*}{$N$} & \multicolumn{3}{|c|}{$\begin{array}{c}\text { Homocysteine, } \mu \mathrm{mol} / \mathrm{L}^{1} \\
\text { Percent relative change of homocysteine }{ }^{2}\end{array}$} & \multicolumn{3}{|c|}{$\begin{array}{l}\text { Difference in change of } \\
\text { Homocysteine at } 4 \text { weeks by } \\
\text { genotypes }\end{array}$} & \multicolumn{3}{|c|}{$\begin{array}{l}\text { Difference in change of } \\
\text { Homocysteine at } 8 \text { weeks by } \\
\text { genotypes }{ }^{3}\end{array}$} \\
\hline & & baseline & 4 weeks & 8 weeks & $\beta$ & $S E$ & $P$ & $\beta$ & $S E$ & $P$ \\
\hline \multicolumn{11}{|l|}{ Control } \\
\hline \multirow[t]{2}{*}{$\mathrm{CC}$} & 41 & $11.6(1.4)[11.3]$ & $11.9(1.3)[11.8]$ & $11.8(1.4)[11.3]$ & & & & & & \\
\hline & & & 3.35(13.7) & $2.2(14.0)$ & ref & & & ref & & \\
\hline \multirow[t]{2}{*}{$\mathrm{CT}$} & 73 & $11.0(1.4)[11.1]$ & $11.2(1.4)[11.3]$ & 11.3(1.4)[11.1] & & & & & & \\
\hline & & & $2.25(13.2)$ & $3.1(14.0)$ & -3.69 & 2.94 & 0.209 & -1.80 & 3.45 & 0.601 \\
\hline \multirow[t]{2}{*}{$\pi$} & 38 & 18.1(1.9)[14.7] \# & 18.0(1.9)[15.6] \# & $18.1(1.8)[16.5]]^{\#}$ & & & & & & \\
\hline & & & 1.19(19.7) & $3.3(27.0)$ & -4.05 & 3.33 & 0.225 & -0.52 & 3.91 & 0.895 \\
\hline \multirow[t]{2}{*}{ Total } & 152 & $12.7(1.6)[12.0]$ & 12.8(1.6)[11.7] & $12.8(1.6)[12.0]$ & & & & & & \\
\hline & & & $2.3(15.1)$ & $2.9(18.0)$ & & & & & & \\
\hline \multicolumn{11}{|l|}{ Low FA } \\
\hline \multirow[t]{2}{*}{ CC } & 34 & $11.0(1.3)[11.0]$ & $9.9(1.3)[9.4]^{*}$ & $9.8(1.3)[9.5] *$ & & & & & & \\
\hline & & & $-8.8(13.0)$ & $-9.9(14.9)$ & ref & & & ref & & \\
\hline \multirow[t]{2}{*}{$\mathrm{CT}$} & 79 & $12.6(1.5)[11.4]$ & $11.5(1.4)[11.1]$ *\# & $11.2(1.4)[10.7] * \# \$$ & & & & & & \\
\hline & & & $-7.6(15.4)$ & $-9.7(16.8)$ & 2.14 & 3.35 & 0.523 & 2.52 & 3.88 & 0.516 \\
\hline \multirow[t]{2}{*}{$\pi$} & 34 & $17.5(1.8)[17.2]{ }^{\#}$ & $15.2(1.7)[14.2]$ *\# & $14.8(1.6)[14.2] * \#$ & & & & & & \\
\hline & & & $-10.6(21.3)$ & $-11.2(27.1)$ & -1.16 & 3.95 & 0.769 & 0.06 & 4.58 & 0.989 \\
\hline \multirow[t]{2}{*}{ Total } & 147 & 13.2(1.6)[11.6] & $11.8(1.5)[11.3] *$ & $11.6(1.5)[10.8] * \$ \%$ & & & & & & \\
\hline & & & $-8.6(16.4) \%$ & $-10.1(19.1) \%$ & & & & & & \\
\hline \multicolumn{11}{|l|}{ High FA } \\
\hline \multirow[t]{2}{*}{ CC } & 39 & $11.0(1.4)[10.8]$ & $10.2(1.4)[10.1]$ * & $9.7(1.4)[9.8] * \$$ & & & & & & \\
\hline & & & $-5.9(14.2)$ & $-10.8(11.1)$ & ref & & & ref & & \\
\hline \multirow[t]{2}{*}{$\mathrm{CT}$} & 69 & $12.3(1.3)[12.0]$ & $10.8(1.3)[11.0] *$ & $10.7(1.3)[10.5] *$ & & & & & & \\
\hline & & & $-11.2(14.5)$ & $-11.2(16.5)$ & -6.21 & 3.19 & 0.052 & -0.47 & 3.39 & 0.890 \\
\hline \multirow[t]{2}{*}{$\pi$} & 38 & $20.8(1.8)[19.6]^{\#}$ & $15.8(1.6)[14.2] * \#$ & $15.4(1.6)[14.1]$ *\# & & & & & & \\
\hline & & & $-20.3(22.2)^{\#}$ & $-22.0(23.8)^{\#}$ & -15.51 & 3.72 & $<0.001$ & -11.12 & 3.95 & 0.005 \\
\hline \multirow[t]{2}{*}{ Total } & 146 & $13.7(1.6)[12.7]$ & $11.7(1.5)[11.4] *$ & $11.5(1.5)[10.8] * \%$ & & & & & & \\
\hline & & & $-12.1(17.5) \%$ & $-13.9(18.1) \%$ & & & & & & \\
\hline
\end{tabular}

${ }^{1}$ Geometric mean (anti-log SD), median in brackets;

${ }^{2}\left[(\text { Homocysteine after treatment - homocysteine at baseline)/(homocysteine at baseline) }]^{*} 100\right.$, Mean(SD);

${ }^{3}$ Regression model was adjusted for age, sex, BMI, baseline SBP, DBP, creatinine, TG, HDL-C, TC, FPG, folate, folate change, MTR A2756G polymorphism and study centers;

*Significantly different from baseline, $P<0.05$; ${ }^{\$}$ Significantly different from week $4, P<0.05$;

"Significantly different from the CC genotype, $P<0.05 ;{ }^{\%}$ Significantly different from control group, $P<0.05$.

$(7.2 \mu \mathrm{mol} / \mathrm{L})$ in the study population (without FA fortification) were lower than those observed in a U.S. population [13] and a Chinese population [14], which means that this Chinese population was not a representative population in which to evaluate the homocysteine lowering effect of FA. In our study, we investigated if the change in plasma homocysteine concentration in response to two commonly used physiological doses $(0.4 \mathrm{mg} / \mathrm{d}$ and $0.8 \mathrm{mg} / \mathrm{d})$ of FA supplementation could be modified by individual MTHFR C677T and MTG A2756G polymorphisms in a multicenter, randomized, double-blind, controlled trial in hypertensive Chinese adults, whose homocysteine concentrations were comparable to the general Chinese population [14].

Consistent with a previous study [15], baseline homocysteine concentration was the major determinant of the homocysteine-lowering effect in all genotypes and FA dosage groups. Subsequently, in the present study, after 4 or 8 weeks of treatment, subjects with MTHFR 677 TT genotype had a significantly greater homocysteine-lowering response than did subjects with CC genotype in the high FA group. However, such a heightened response was not shown in the low FA group. Furthermore, when we further adjusted baseline homocysteine, subjects with TT genotype seemed to have a more attenuated homocysteine-lowering response than did subjects with CC genotype in the low FA group but not in the high FA group. The molecular mechanisms that underlie clinical remediation of enzyme variants are the ability of elevated levels of the cofactor or substrate to overcome the binding defects of $\mathrm{Km}$ mutants or to serve as a chemical chaperone to 
Table 3 Response of plasma Homocysteine to different doses and duration of folic acid supplementation by MTR A2756G genotypes

\begin{tabular}{|c|c|c|c|c|c|c|c|c|c|c|}
\hline & \multirow[t]{2}{*}{$\mathbf{N}$} & \multicolumn{3}{|c|}{$\begin{array}{l}\text { Homocysteine, } \mu \mathrm{mol} / \mathrm{L}^{1} \\
\text { Percent relative change of homocysteine }\end{array}$} & \multicolumn{3}{|c|}{$\begin{array}{l}\text { Difference in change of } \\
\text { Homocysteine at } 4 \text { weeks by } \\
\text { genotypes }{ }^{3}\end{array}$} & \multicolumn{3}{|c|}{$\begin{array}{c}\text { Difference in change of } \\
\text { Homocysteine at } 8 \text { weeks by } \\
\text { genotypes }{ }^{3}\end{array}$} \\
\hline & & baseline & 4 weeks & 8 weeks & $\beta$ & SE & $P$ & $\beta$ & SE & $P$ \\
\hline \multicolumn{11}{|l|}{ Control } \\
\hline \multirow[t]{2}{*}{ AA } & 130 & 12.8(1.6)[12.0] & $12.9(1.6)[11.7]$ & $12.9(1.6)[12.0]$ & & & & & & \\
\hline & & & $1.7(15.1)$ & 2.33(17.7) & ref & & & ref & & . \\
\hline \multirow[t]{2}{*}{$A G / G G$} & 22 & $12.1(1.5)[11.7]$ & $12.6(6.8)[1.6]$ & $12.6(1.5)[12.2]$ & & & & & & \\
\hline & & & $5.8(15.2)$ & $6.32(20.1)$ & 5.17 & 3.50 & 0.139 & 6.08 & 4.10 & 0.138 \\
\hline \multirow[t]{2}{*}{ Total } & 152 & $12.7(1.6)[12.0]$ & $12.8(1.6)[11.7]$ & $12.8(1.6)[12.0]$ & & & & & & \\
\hline & & & $2.3(15.1)$ & $2.9(18.0)$ & & & & & & \\
\hline \multicolumn{11}{|l|}{ Low FA } \\
\hline \multirow[t]{2}{*}{ AA } & 116 & $12.9(1.6)[11.5]$ & $11.5(1.5)[11.1]^{*}$ & $11.3(1.5)[10.6] *$ & & & & & & \\
\hline & & & $-9.4(16.5)$ & $-10.2(19.4)$ & ref & & & ref & & \\
\hline \multirow[t]{2}{*}{$A G / G G$} & 31 & $14.1(1.5)[14.5]$ & $13.1(1.5)[12.3]$ & $12.5(1.5)[12.3] * \$$ & & & & & & \\
\hline & & & $-5.4(15.9)$ & $-9.6(18.3)$ & 3.73 & 3.33 & 0.262 & -0.06 & 3.86 & 0.989 \\
\hline \multirow[t]{2}{*}{ Total } & 147 & 13.2(1.6)[11.6] & $11.8(1.5)[11.3] *$ & $11.6(1.5)[10.8] * \$ \%$ & & & & & & \\
\hline & & & $-8.6(16.4) \%$ & $-10.1(19.1) \%$ & & & & & & \\
\hline \multicolumn{11}{|l|}{ High FA } \\
\hline \multirow[t]{2}{*}{ AA } & 119 & $13.7(1.6)[12.7]$ & $11.8(1.5)[11.4] *$ & $11.5(1.4)[10.8] * \$$ & & & & & & \\
\hline & & & $-12.3(16.2)$ & $-14.4(17.3)$ & ref & & & ref & & \\
\hline \multirow[t]{2}{*}{ AG/GG } & 27 & $13.5(1.8)[12.9]$ & $11.6(1.5)[11.4] *$ & $11.5(1.5)[10.7] *$ & & & & & & \\
\hline & & & $-11.5(22.7)$ & $-11.9(21.5)$ & 1.30 & 3.39 & 0.700 & 2.72 & 3.60 & 0.450 \\
\hline \multirow[t]{2}{*}{ Total } & 146 & $13.7(1.6)[12.7]$ & $11.7(1.5)[11.4] *$ & $11.5(1.5)[10.8] * \%$ & & & & & & \\
\hline & & & $-12.1(17.5) \%$ & $-13.9(18.1)^{\%}$ & & & & & & \\
\hline
\end{tabular}

${ }^{1}$ Geometric mean (anti-log SD), median in brackets;

${ }^{2}[(\text { Homocysteine after treatment - homocysteine at baseline }) /(\text { homocysteine at baseline })]^{*} 100$, Mean(SD);

${ }^{3}$ Regression model was adjusted for age, sex, BMI, baseline SBP, DBP, creatinine, TG, HDL, TC, FPG, MTHFR C677T polymorphism and study centers;

*Significantly different from baseline, $P<0.05$; ${ }^{\$}$ Significantly different from week $4, P<0.05$;

${ }^{\%}$ Significantly different from control group, $P<0.05$.

improve the stability of mutant enzyme variants $[16,17]$. Our results further suggest that daily $0.4 \mathrm{mg}$ FA supplementation may be insufficient, and that a daily dose of 0.8 mg FA may be required to lower homocysteine concentration in subjects with TT genotype.

Furthermore, after the treatment, subjects with CT genotype had significantly higher homocysteine concentrations than those with CC genotype in the low FA group, and had similar homocysteine concentrations as CC subjects in the high FA group. These results indicate that daily $0.8 \mathrm{mg}$ FA also may be necessary for lowering homocysteine concentration in subjects with CT genotypes. However, although they showed a greater homocysteine lowering effect than subjects with CC genotype, subjects with TT genotype still had the highest homocysteine concentrations even after 8 weeks of high FA treatment. Therefore, other therapeutic strategies need to be developed to reduce the risk associated with hyperhomocysteinemia in TT subjects.

In fact, Malinow et al. [18] first reported that TT subjects experienced much greater decreases in plasma total homocysteine concentrations after receiving FA at a dose of 1 or
$2 \mathrm{mg} / \mathrm{d}$ for 3 weeks than did CC subjects. Among subjects who were not previously taking multivitamins, the mean reductions in plasma total homocysteine concentrations were $-20.9 \%,-13.1 \%$, and $-7.1 \%$ in persons with the TT, $\mathrm{CT}$, and $\mathrm{CC}$ genotypes, respectively $(P=0.019$ for TT versus (C). A similar result also has been reported in a study in Taiwan, in which $5 \mathrm{mg}$ of FA daily were supplemented for 8 wks [19]. Our results appear to be consistent with these studies. However, the study of Woodside et al. [20] showed that TT subjects are less responsive to the effects of FA and B-vitamin supplementation (daily $1 \mathrm{mg}$ FA, 7.2 mg Vitamin B6, and $0.02 \mathrm{mg}$ Vitamin B12 for 8 wks.) than CC subjects. And Ho GY et al. [21] also reported that MTHFR C677T did not impact the total homocysteinelowering effect of vitamins (daily $2.5 \mathrm{mg}$ FA, $25 \mathrm{mg}$ Vitamin B6, and $0.5 \mathrm{mg}$ Vitamin B12 for 1 year) in a study performed in Singapore. The reasons for the disparities among the results of these studies are unknown. Additional large dose-finding studies are required to further elucidate the possible contributory factors, such as folate status, ethnicity of the participants, and in particular the possible effects of concomitant vitamin B6 and/or B12. 
Our study showed that neither homocysteine concentration at baseline or post-FA treatment nor the homocysteine lowering response of FA supplementation was affected by MTR A2756G polymorphism. However, there was a significant homocysteine reduction in MTR 2756 AG/GG genotype after 4 weeks of FA supplementation in the high FA $(0.8 \mathrm{mg} / \mathrm{d})$ group, but not in the low FA $(0.4 \mathrm{mg} / \mathrm{d})$ group, which means that we cannot exclude the possible role of MTR A2756G polymorphism in the homocysteine metabolic pathway.

Overall, our results suggest that daily $0.8 \mathrm{mg}$ FA may be necessary to lower homocysteine concentration for Chinese hypertensive subjects with CT or TT genotype, which have important clinical and public health implications. Increased homocysteine concentration has been implicated as a risk factor for neural tube defects (NTDs) and Downs syndrome [22,23]. A study by Wilcken et al. reported that the frequency of CT and TT genotypes in Hungary was about $45 \%$ and $11.1 \%$, respectively [24]. Two Hungarian intervention trials $[25,26]$, which used a multivitamin containing $0.8 \mathrm{mg}$ folic acid, found a significant reduction in the first occurrence of urinary tract and cardiovascular abnormalities beyond the $90 \%$ reduction of NTDs. There is no evidence that $0.4 \mathrm{mg}$ folic acid has a similar preventive effect on defects beyond NTDs. Our results further suggest that there may be an additional benefit if a daily dose of $0.8 \mathrm{mg}$, but not $0.4 \mathrm{mg}$, of folic acid could be used in women, particularly in populations with a high frequency of $\mathrm{T}$ allele (such as the Chinese) and without folic acid fortification. Furthermore, identifying TT or CT subjects and providing them with an optimal dose of folic acid also may be very important in the prevention of CVD $[4,27]$ in populations without folic acid fortification.

Our study has the following strengths. This was a randomized, multicenter and double blind trial. This study simultaneously assessed the effect of FA dosages and gene polymorphisms on homocysteine-lowering efficacy. Our trial studied two commonly used doses of FA, which are of important clinical and public health relevance. However, caution is needed in generalizing our findings from this hypertensive Chinese population to other populations. Furthermore, though similar results were obtained when we restricted our analyses to subjects who fully complied with the protocol during the treatment periods, we still could not fully exclude the effect of non-compliance problem on our results. Also, it should be noted that we did not measure other polymorphisms in the folate pathway, such as the MTHFR A1298C variant. Furthermore, the treatment period with FA was only 8 weeks and the sample size was rather small when sub-grouped into various groups (control, low FA and high FA) for genetic association studies. Future studies with longer treatment duration and a larger sample size are needed to confirm our results. The association between angiotensin-converting enzyme inhibitor treatment and the change of homocysteine was controversial $[28,29]$. We did not observe a significant relationship between enalapril treatment and homocysteine change in our study.. Additional large sample studies also are needed to further examine the relationship of enalapril treatment with homocysteine change and the possible interactive effects between enalapril and folic acid on the change in homocysteine.

\section{Conclusions}

We demonstrated that MTHFR C677T polymorphisms can not only affect plasma homocysteine levels at baseline and post-FA treatment, but also modify therapeutic response to various dosages of FA supplementation. These findings, if confirmed by additional studies, may enable medical providers to offer more personalized care and advice on FA supplementation for a given individual.

\section{List of abbreviations}

Cl: Confidence Interval; CVD: cardiovascular disease; FA: folic acid; MTHFR: methylenetetrahydrofolate reductase; MTR: methionine synthase; RR: Relative Risk.

\section{Acknowledgements}

The study was supported by Beijing Huaanfo Biomedical Research Center Inc., Beijing, China and in part by a grant from Anhui Provincial Ministry of Education (No. 2002kj174ZC), Anhui Provincial Ministry of Science and Technology, Anhui Medical University Biomedical Institute. The sponsors did not participate in the design or conduct of the study; collection, management, analysis, and interpretation of the data; or preparation, review, and approval of the manuscript. We gratefully acknowledge the assistance and cooperation of the faculty and staff of the Anhui Medical University and thank all of the participants in our study. This study was conducted in accordance with the current regulations of the People's Republic of China.

\section{Author details}

${ }^{1}$ Institute of Biomedicine, Anhui Medical University, Hefei, China.

${ }^{2}$ Department of Cardiology and Heart Center, Peking University First Hospital, Beijing, China. ${ }^{3}$ Department of Pharmacy, Peking University First Hospital, Beijing, China. ${ }^{4}$ Department of Pharmacy, First Affiliated Hospital of Academy of Military Medical, Sciences of China, Beijing, China. ${ }^{5}$ Department of Pharmacy, Beijing Tiantan Hospital, Capital Medical University, Beijing, China. ${ }^{6}$ Department of Cardiology, Zhongshan Hospital Fudan University, Shanghai, China. ${ }^{7}$ Department of Cardiology, First Clinical Medical College of Harbin Medical University, Harbin, China. ${ }^{8}$ Department of Cardiology, First Affiliated Hospital of China Medical University, Shenyang, China. ${ }^{9}$ Department of Cardiology, First Affiliated Hospital of the School of Medicine, Xi'an Jiaotong University, Xi'an, China. ${ }^{10}$ Department of Cardiology, First Affiliated Hospital of Nanjing Medical University, Nanjing, China. ${ }^{11}$ Guangdong Institute of Nephrology, Southern Medical University, Guangzhou, China. ${ }^{12}$ Mary Ann and J. Milburn Smith Child Health Research Program, Children's Memorial Hospital and Children's Memorial Research Center, Department of Pediatrics, Northwestern University Feinberg School of Medicine, Chicago, USA.

\section{Authors' contributions}

$Q X, L J, C Y, L Z, Z Z, G J, G D, H J, W Y, Z F, X X, W X, X X$ and $H Y$ participated in the design of the study; LJ, CY, LZ, GJ, GD, HJ, WY, ZF, HY conducted the study; $Q X, L J, X X u, W X, X X u$ and $Y H$ analyzed data; $Q X, L J, C Y, L Z, Z Z, G J, G D, H J$, $W Y, Z F, X X, W X, X X$ and $H Y$ wrote the paper; all authors read and approved the final manuscript. 


\section{Competing interests}

The authors declare that they have no competing interests.

Received: 26 August 2011 Accepted: 10 January 2012

Published: 10 January 2012

\section{References}

1. Tolonen H, Mähönen M, Asplund K, Rastenyte D, Kuulasmaa K, Vanuzzo D, Tuomilehto J: Do trends in population levels of blood pressure and other cardiovascular risk factors explain trends in stroke event rates? Comparisons of 15 populations in 9 countries within the WHO MONICA Stroke Project. World Health Organization Monitoring of Trends and Determinants in Cardiovascular Disease. Stroke 2002, 33:2367-2375.

2. Wald DS, Law M, Morris JK: Homocysteine and cardiovascular disease: evidence on causality from a meta-analysis. BMJ 2003, 325:1202-1206.

3. Towfighi A, Markovic D, Ovbiagele B: Pronounced association of elevated serum homocysteine with stroke in subgroups of individuals: a nationwide study. J Neurol Sci 2010, 298:153-157.

4. Wang X, Qin X, Demirtas H, Li J, Mao G, Huo Y, Sun N, Liu L, Xu X: Efficacy of folic acid supplementation in stroke prevention: a meta-analysis. Lancet 2007, 369:1876-1882.

5. Qin $X$, Huo $Y$, Langman CB, Hou F, Chen $Y$, Matossian $D$, Xu X, Wang X: Folic acid therapy and cardiovascular disease in ESRD or Advanced Chronic Kidney Disease: A Meta-Analysis. Clin J Am Soc Nephrol 2011, 6:482-488.

6. Hustad S, Midttun $\varnothing$, Schneede J, Vollset SE, Grotmol T, Ueland PM: The methylenetetrahydrofolate reductase $677 \mathrm{C} \rightarrow>$ T polymorphism as a modulator of a B vitamin network with major effects on homocysteine metabolism. Am J Hum Genet 2007, 80:846-855.

7. Barbosa PR, Stabler SP, Machado AL, Braga RC, Hirata RD, Hirata MH, Sampaio-Neto LF, Allen RH, Guerra-Shinohara EM: Association between decreased vitamin levels and MTHFR, MTR and MTRR gene polymorphisms as determinants for elevated total homocysteine concentrations in pregnant women. Eur J Clin Nutr 2008, 62:1010-1021.

8. Mao G, Hong X, Xing H, Liu P, Liu H, Yu Y, Zhang S, Jiang S, Wang X, Xu X: Efficacy of folic acid and enalapril combined therapy on reduction of blood pressure and plasma glucose: a multicenter, randomized, doubleblind, parallel-controlled, clinical trial. Nutrition 2008, 24:1088-1096.

9. Qin X, Li J, Cui Y, Liu Z, Zhao Z, Ge J, Guan D, Hu J, Wang Y, Zhang F, Xu X, Wang $X, X u X$, Huo Y: Effect of folic acid intervention on the change of serum folate level in hypertensive Chinese adults: do methylenetetrahydrofolate reductase and methionine synthase gene polymorphisms affect therapeutic responses? Pharmacogenet Genomics 2011.

10. Tighe P, Ward M, McNulty H, Finnegan O, Dunne A, Strain J, Molloy AM, Duffy M, Pentieva K, Scott JM: A dose-finding trial of the effect of longterm folic acid intervention: implications for food fortification policy. Am J Clin Nutr 2011, 93:11-18.

11. Anderson CA, Jee SH, Charleston J, Narrett M, Appel L: Effects of folic acid supplementation on serum folate and plasma homocysteine concentrations in older adults: a dose-response trial. Am J Epidemiol 2010, 172:932-941.

12. Crider KS, Zhu JH, Hao L, Yang QH, Yang TP, Gindler J, Maneval DR, Quinlivan EP, Li Z, Bailey LB, Berry RJ: MTHFR 677C-> T genotype is associated with folate and homocysteine concentrations in a large, population-based, double-blind trial of folic acid supplementation. Am J Clin Nutr 2011, 93:1365-1372.

13. Jacques PF, Rosenberg $\mathbb{H}$, Rogers $G$, Selhub J, Bowman BA, Gunter EW, Wright JD, Johnson CL: Serum total homocysteine concentrations in adolescent and adult Americans: results from the third National Health and Nutrition Examination Survey. Am J Clin Nutr 1999, 69:482-489.

14. Hao L, Ma J, Zhu J, Stampfer MJ, Tian Y, Willett WC, Li Z: High prevalence of hyperhomocysteinemia in Chinese adults is associated with low folate, vitamin B-12, and vitamin B-6 status. J Nutr 2007, 137:407-413.

15. Homocysteine Lowering Trialists' Collaboration: Lowering blood homocysteine with folic acid based supplements: meta-analysis of randomised trials. BMJ 1998, 316:894-898.

16. Marini NJ, Gin J, Ziegle J, Keho KH, Ginzinger D, Gilbert DA, Rine J: The prevalence of folate-remedial MTHFR enzyme variants in humans. Proc Natl Acad Sci USA 2008, 105:8055-8060.
17. Ames BN, Elson-Schwab I, Silver EA: High-dose vitamin therapy stimulates variant enzymes with decreased coenzyme binding affinity (increased $\mathrm{K}$ $(\mathrm{m}))$ : relevance to genetic disease and polymorphisms. Am J Clin Nutr 2002, 75:616-658.

18. Malinow MR, Nieto FJ, Kruger WD, Duell PB, Hess DL, Gluckman RA, Block PC, Holzgang CR, Anderson PH, Seltzer D, Upson B, Lin QR: The effects of folic acid supplementation on plasma total homocysteine are modulated by multivitamin use and methylenetetrahydrofolate reductase genotypes. Arterioscler Thromb Vasc Biol 1997, 17:1157-1162.

19. Liu CS, Chiang HC, Chen HW: Methylenetetrahydrofolate reductase polymorphism determines the plasma homocysteine-lowering effect of large-dose folic acid supplementation in patients with cardiovascular disease. Nutrition 2004, 20:974-978.

20. Woodside JV, Yarnell JW, McMaster D, Young IS, Harmon DL, McCrum EE, Patterson CC, Gey KF, Whitehead AS, Evans A: Effect of B-group vitamins and antioxidant vitamins on hyperhomocysteinemia: a double-blind, randomized, factorial-design, controlled trial. Am J Clin Nutr 1998, 6:858-866.

21. Ho GY, Eikelboom JW, Hankey GJ, Wong CR, Tan SL, Chan JB, Chen CP: Methylenetetrahydrofolate reductase polymorphisms and homocysteinelowering effect of vitamin therapy in Singaporean stroke patients. Stroke 2006, 37:456-460.

22. Mills JL, McPartlin JM, Kirke PN, Lee YJ, Conley MR, Weir DG, Scott JM: Homocysteine metabolism in pregnancies complicated by neural-tube defects. Lancet 1995, 345:149-151.

23. Bosco P, Guéant-Rodriguez RM, Anello G, Barone C, Namour F, Caraci F, Romano A, Romano C, Guéant JL: Methionine synthase (MTR) 2756 (A -> G) polymorphism, double heterozygosity methionine synthase $2756 \mathrm{AG} /$ methionine synthase reductase (MTRR) $66 \mathrm{AG}$, and elevated homocysteinemia are three risk factors for having a child with Down syndrome. Am J Med Genet A 2003, 121:219-224.

24. Wilcken B, Bamforth F, Li Z, Zhu H, Ritvanen A, Renlund M, Stoll C, Alembik Y, Dott B, Czeizel AE, Gelman-Kohan Z, Scarano G, Bianca S, Ettore G, Tenconi R, Bellato S, Scala I, Mutchinick OM, Lopez MA, de Walle H, Hofstra R, Joutchenko L, Kavteladze L, Bermejo E, MartinezFrias ML, Gallagher M, Erickson JD, Vollset SE, Mastroiacovo P, Andria G, Botto LD: Geographical and ethnic variation of the $677 \mathrm{C}>$ T allele of 5,10 methylenetetrahydrofolate reductase (MTHFR): findings from over 7000 newborns from 16 areas world wide. J Med Genet 2003, 40:619-625.

25. Czeizel AE, Dudás I: Prevention of the first occurrence of neural-tube defects by periconceptional vitamin supplementation. N Engl J Med 1992, 327:1832-1835.

26. Czeizel AE, Dobo M, Vargha P: Hungarian cohort-controlled trial of periconceptional multivitamin supplementation shows a reduction in certain congenital abnormalities. Birth Defects Res A Clin Mol Teratol 2004, 70:853-861.

27. Wald DS, Wald NJ, Morris JK, Law M: Folic acid, homocysteine, and cardiovascular disease: judging causality in the face of inconclusive trial evidence. BMJ 2006, 333:1114-1117.

28. Poduri A, Kaur J, Thakur JS, Kumari S, Jain S, Khullar M: Effect of ACE inhibitors and beta-blockers on homocysteine levels in essential hypertension. J Hum Hypertens 2008, 22:289-294.

29. Westphal S, Rading A, Luley C, Dierkes J: Antihypertensive treatment and homocysteine concentrations. Metabolism 2003, 52:261-263.

doi:10.1186/1475-2891-11-2

Cite this article as: Qin et al:: MTHFR C677T and MTR A2756G polymorphisms and the homocysteine lowering efficacy of different doses of folic acid in hypertensive Chinese adults. Nutrition Journal 2012 11:2. 